\title{
O ETNOCONHECIMENTO GEOMORFOLÓGICO APLICADO AO ORDENAMENTO TERRITORIAL NAS PEQUENAS COMUNIDADES TRADICIONAIS
}

\author{
GEOMORPHOLOGICAL ETHNO-KNOWLEDGE \\ APPLIED TO TERRITORIAL PLANNING IN \\ SMALL TRADITIONAL COMMUNITIES
}

\author{
Simone Cardoso Ribeiro ${ }^{1}$ \\ simonecribeiro@oi.com.br \\ Sinara Gomes de Sousa ${ }^{2}$ \\ sinarageogomes@live.com
}

\begin{abstract}
The present work focuses on two concepts, that of ethno-geomorphology and that of territorial planning. At first a geoenvironmental characterization of the municipalities was conducted in order to recognize the physical/natural and social aspects of the surveyed areas; following controlled interviews were applied using the 'Snowball' technique and data evaluation. Altogether, 77 rural producers were interviewed, 54 in the municipality of Farias Brito and 23 in the municipality of Granjeiro, State of Ceará. The study highlighted the importance of the valorization of popular knowledge, as pointed out by the attitude of the drylands peasants, who apply their knowledge of the potentialities and limitations of the ecosystem in order to plan and organize their territory searching to improve the viability of their economic activities, coupled with the conservation of the environmental resources.
\end{abstract}

Keywords: Ethnogeomorphology; Planning; Use and soil occupation.

${ }^{1}$ Docente, Departamento de Geociências, URCA.

${ }^{2}$ Discente, Programa de Pós-Graduação em Geografia, UFPE. 


\section{RESUMO}

O presente trabalho debruça-se sobre dois conceitos, o de Etnogeomorfologia e o de ordenamento territorial. Primeiramente fizemos a caracterização geoambiental dos municípios para reconhecimento dos aspectos físico/naturais e sociais das áreas pesquisadas; aplicação de entrevistas roteirizadas utilizando a técnica 'Bola de Neve'; e levantamento dos dados. No total foram entrevistados 77 produtores rurais. Destaca-se aqui, a importância da valorização do saber popular, pois os sertanejos como conhecedores das potencialidades e limitações do ecossistema, planejam e ordenam seu território na busca de uma melhor viabilização de suas atividades econômicas, tendo em vista a conservação do meio ambiente.

Palavras-chave: Etnogeomorfologia; Ordenamento; Uso e ocupação do solo.

\section{CONTEXTO DA PESQUISA}

O presente trabalho debruça-se sobre dois conceitos-chave, o de Etnogeomorfologia e o de ordenamento territorial. Em que ambos dentro do foco desta pesquisa, se complementam pelo fato de que o pequeno produtor rural com base no seu conhecimento sobre o relevo local e os processos morfoesculturadores atuantes, determinam a qualidade do solo, que tipo de cultivo, no caso da agricultura, ou atividade pecuarista deverá ser feito nessas áreas. Os sertanejos com base nos seus saberes vernaculares e empirismo conhecem as limitações e potencialidades de cada compartimento geomórfico da paisagem que o circunda.

As temáticas relacionadas ao ordenamento territorial são amplamente debatidas no cenário geográfico. No âmbito da Geografia Física, essa questão está associada à organização do espaço, principalmente, quando se trata das atividades econômicas de uso e ocupação do solo em detrimento das condições ambientais, sempre que 
essas atividades não respeitam as limitações do ambiente, portanto, as práticas de planejamento e gestão são fases essenciais no processo de ordenamento territorial, pois tem como objetivo:

[...] caracterizar e avaliar problemas em um determinado espaço, visando organizar e administrar o uso e a ocupação deste espaço, considerando as condições dos recursos naturais, a dinâmica social, a estrutura produtiva e o sistema de assentamento da população (BRANDÃO et al, 2001, p. 07).

Ainda de acordo com os autores supracitados, o alcance desse objetivo se dará por meio da implementação de medidas que estimulem as atividades socioeconômicas na realidade espacial pesquisada, visando o bem-estar social, o manejo adequado dos recursos e a qualidade de vida da população (BRANDÃO et al, 2001).

Dentro da perspectiva de planejamento econômico e ambiental do território, o ordenamento territorial consiste no planejamento das intervenções humanas, tomando-se como premissas a potencialidade dos recursos naturais e humanos e as fragilidades dos ambientes (ROSS, 1993).

Em se tratando de práticas de organização social, econômica e ambiental do território, a junção entre o ordenamento territorial e os estudos etnogeomorfológicos trazem a tona uma discussões que contempla a relação sociedade e natureza. Pois, a Etnogeomorfologia é um ramo da ciência 
geomorfológica que se dedica a compreender com se são as relações entre comunidades tradicionais e a paisagem que os circundam. Esta é definida como:

[...] ciência híbrida, que estuda o conhecimento que a uma comunidade tem acerca dos processos geomorfológicos, levando em consideração os saberes sobre a natureza e os valores da cultura e da tradição locais, sendo a base antropológica da utilização das formas de relevo por dada cultura (RIBEIRO, 2014, p. 51).

Trata-se dos registros memorais de povos que possuem uma relação de interdependência com a natureza e que desenvolvem suas atividades agrosilvipastoris com base nos seus conhecimentos vernaculares, e a partir deles "percebem, concebem e conceituam os recursos, paisagens ou ecossistemas dos quais dependem para subsistir" (TOLEDO; BARRERA-BASSOLS, 2009, p. 35).

As pesquisas de cunho etnográfico tem se disseminado no âmbito de várias ciências. Dentro da arqueologia, Miller (2009) descreve os estudos etnoarqueológicos desenvolvidos em sociedades vivas que possuem a mesma credibilidade dos estudos realizados em sítios escavados. Relata também que existem comunidades que ao serem alvos de investigações sobre sua cultura e modo de vida apresentam traços de civilizações antigas que residiram naquele território há séculos, mostrando uma mistura de tradições.

Quanto à etnogeomorfologia aqui apresentada, não se sabe ao certo a origem dos saberes que os sertanejos trazem consigo, sabe-se apenas que estes thes foram 
repassados pelos seus genitores que também aprenderam com seus antecedentes a partir da oralidade e do trabalho empírico. Porém abre caminho para investigações direcionadas a busca das raízes de cada comunidade, de sua cultura, e do seu conhecimento etnogeomórfico.

Este trabalho apresenta em seu conteúdo parte dos resultados obtidos durante dois anos de pesquisa sobre os conhecimentos tradicionais dos produtores rurais familiares sobre o relevo local, os processos geomórficos atuantes, e como esses processos influenciam nas suas atividades agropecuárias nos municípios de Farias Brito e Granjeiro, sul do Ceará, tendo como objetivo principal investigar se além das limitações impostas pelo clima semiárido nordestino, o relevo também exerce influencia nessas atividades.

\section{ÁREA DE ESTUDO}

Os municípios abordados aqui localizam-se na Região do Cariri, sul do estado do Ceará. Farias Brito possui estimativa populacional de 18.789 habitantes, onde grande parte residem nas áreas rurais, e extensão territorial de $503,7 \mathrm{~km}^{2}$, enquanto Granjeiro possui área absoluta de $100,3 \mathrm{~km}^{2}$ e comporta em seu território aproximadamente 4.459 habitantes, a maioria também residindo na zona rural do município (IPECE, 2015ab; IBGE, 2016ab). 


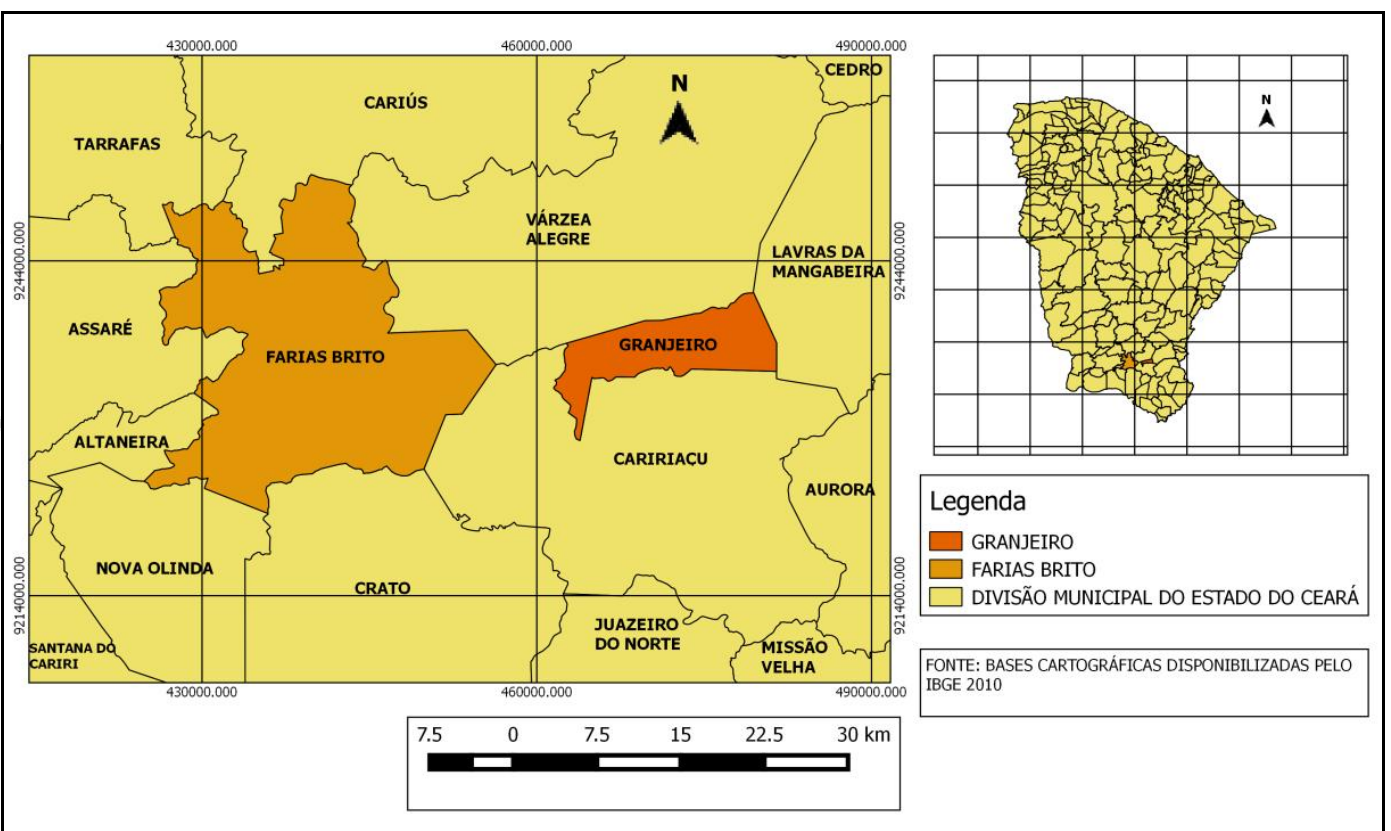

Figura 1: Mapa de localização dos municípios de Farias Brito e Granjeiro/CE. Fonte: Macedo, 2015.

A escolha desses municípios se deu por terem eu seu território pequenas comunidades tradicionais que mantém suas atividades econômicas de subsistência ligadas ao uso dos recursos naturais, como a agricultura, pecuária e em alguns casos o extrativismo vegetal.

Em relação às características geoambientais, o clima predominante nos municípios é o Tropical Quente Semiárido e Tropical Quente Semiárido brando (IPECE, 2007). No município de Granjeiro o clima é mais ameno, a pluviosidade média anual ultrapassa os $1.000 \mathrm{~mm}$, com variação térmica de $24^{\circ}$ a $26^{\circ} \mathrm{C}$. Em 
Farias Brito, a semiaridez se faz mais presente, onde a média pluviométrica anual gira em torno de $890 \mathrm{~mm}$ e variação térmica de $26^{\circ}$ a $28^{\circ} \mathrm{C}$ (IPECE, 2015ab).

A geomorfologia dos dois municípios é marcada pela presença de Maciços Residuais e Depressões Sertanejas. No município de Farias Brito o maciço residual, conhecido popularmente como Serra do Quincunca, possui cotas altimétricas que atingem os $670 \mathrm{~m}$ e um pequeno platô em superfície. Os maciços presentes no município de Granjeiro correspondem a extensões da Serra de São Pedro, município de Caririaçu, e em alguns pontos atinge uma altimetria semelhante ao do maciço Serra do Quincuncá.

Em relação às classes de solo predominantes nos dois municípios, podemos citar o Neossolo Litólico, Neossolo Flúvico, Argissolo Vermelho Eutrófico e Distrófico. O Nitossolo Vermelho aparece como uma particularidade no município de Farias Brito (FUNCEME, 2012). E quanto à cobertura vegetal, há o predomínio da Caatinga arbóreo-arbustiva, Caatinga Arbustiva densa e Floresta Caducifólia espinhosa (FUNCEME, 2006).

\section{MATERIAIS E MÉTODOS}

O mapeamento dos municípios foi feito utilizando bases cartográficas disponibilizadas pelo Instituto Brasileiro de Geografia e Estatística - IBGE, Fundação Cearense de Meteorologia e Recursos Hídricos - FUNCEME e 
interpretação de imagens SRTM, disponibilizadas pela Empresa Brasileira de Pesquisa em Agropecuária -EMBRAPA.

Os mapas e dados sobre a cobertura vegetal e uso e ocupação do solo foram obtidos através da utilização do software ArcGis (licença obtida pelo laboratório de Geomorfologia e Pedologia - Geoped), usando os dados disponibilizados pela FUNCEME no zoneamento geoambiental da mesorregião do sul cearense realizado em 2006. As informações sobre as classes de solos foram retiradas de mapas produzidos pela FUNCEME, em seu trabalho intitulado: Levantamento de Reconhecimento de Média Intensidade de Solos - Mesorregião do Sul Cearense em 2012.

As referências sobre o relevo foram produzidas através da interpretação de imagens SRTM (MIRANDA, 2005), que também foram utilizadas na produção do Mapa Hipsométrico, também tratado no ArcGis. Foi feito o esboço de perfis topográficos no software Global Mapper 16 para a aferição das cotas altimétricas e também para demonstração das unidades etnogeomorfológicas identificadas.

Para aplicação das entrevistas roteirizadas foi utilizada a técnica 'Bola de Neve', que consiste num processo onde o primeiro entrevistado indica o segundo e assim sucessivamente. As perguntas são relacionadas principalmente aos processos morfoesculturadores do relevo, a geomorfologia local e ao uso e manejo do solo, além de questões sobre clima, vegetação, hidrografia, etc. As entrevistas 
roteirizadas serviram apenas para nortear o diálogo, tornando o processo menos formal, de forma a deixar o entrevistado à vontade para explicar a seu modo, no seu linguajar, as suas experiências e conhecimentos vernaculares acerca da dinâmica ambiental da sua localidade.

No total foram entrevistados 54 produtores rurais no município de Farias Brito, em seis comunidades, e 23 no município de Granjeiro, sendo três comunidades pesquisadas, totalizando ao final 77 entrevistados. Essa disparidade entre a quantidade de entrevistados e comunidades pesquisadas se deu pelo fato de o segundo município citado ser bem menos populoso em relação ao primeiro.

O levantamento dos conhecimentos etnogeomorfológicos foi feito através de produções textuais dos dados obtidos em cada comunidade pesquisada. Buscamos agrupar todas as informações referentes à relação entre o relevo e as formas de uso e ocupação do solo que refletem o ordenamento territorial feito pelos produtores rurais. E por fim, foram traçados perfis topográficos demonstrativos das unidades etnogeomorfológicas descritas.

\section{RESULTADOS E DISCUSSÕES:}

Após a análise dos dados, ficou constatado que em todas as comunidades, os produtores entrevistados compartimentam a paisagem em unidades etnogeomorfológicas de acordo com sua altimetria e ainda the atribuem nomenclaturas próprias de sua cultura. Além disso, também descrevem o tipo de 
solo presente em cada local, indicando o seu teor de fertilidade, quais cultivos podem ser feitos e como deve ser feito o manejo desse solo, além de atribuir-lhes nomenclaturas específicas que remetem a cor do solo, sua textura ou mesmo a sua fertilidade. Fazendo também a identificação e denominação dos processos morfoesculturadores, de acordo com a intensidade, e ainda apontando suas causas.

A descrição das compartimentações e suas respectivas características estão expostas de acordo com os distritos de cada município.

No distrito de Quincunca, município de Farias Brito, foram pesquisadas três comunidades, sítio Extrema, sítio Timbaúbas e sítio tabuleiro. No total foram descritas pelos produtores rurais quatro unidades etnogeomorfológicas.

Chapada - Corresponde as áreas localizadas na cimeira do Maciço Residual (Serra do Quincuncá), possuindo as maiores altimetrias de toda a formação e declividades reduzidas. Nessas áreas há o predomínio do Nitossolo Vermelho, descritos por eles como um solo avermelhado, profundo e fértil, denominado de "terra vermelha". Apesar da pouca declividade, foram relatados processos erosivos, (regos, buracos), pois são nessas áreas que é feita a aragem do solo, deixando-o mais vulnerável a ação da água. É usado no cultivo do milho, feijão, fava, amendoim, jerimum. 
Morro - Colina residual, que sucede e faz parte da formação do maciço. São áreas mais dissecadas e geomorfologicamente instáveis, pois ainda sofrem com processos de erosão linear, suas cotas altimétricas são menores em relação ao maciço. Não houve relatos sobre o tipo de solo dessa área, pois os produtores não tem acesso a ela, portanto não a conhecem detalhadamente, assim como também não relataram a presença de processos erosivos nessas áreas. Devido à declividade acentuada, se tornam áreas de difícil acesso, portanto não são cultivadas.

Quebrada - Encostas íngremes, que sucedem toda e qualquer elevação. Presentes no maciço, colinas e morros residuais. Esta se encontra, na paisagem local, entre a "chapada" e o "baixi". Nessas áreas são encontrados três tipos de solo descritos pelos produtores: a "terra preta" e a "terra vermelha", (Nitossolo Vermelho) ambas férteis, fáceis de manejar, macias, e a "terra ariúsca" (Neossolo Litólico) de cor esbranquiçada, baixa fertilidade, e pedregosa. Aqui, os processos morfoesculturadores do tipo erosivo ocorrem com frequência principalmente nas áreas onde cultivam, pois além da influencia da declividade o solo fica "descoberto" (desnudo), vulnerável a ação das chuvas. E são denominadas de "grotas" (voçorocas e ravinas) "regos" (microrravinas) e "buracos" (sulcos). É usado no cultivo do milho, feijão, fava, jerimum.

Baixio - Áreas mais rebaixadas do relevo, onde se localizam as redes naturais de drenagem e os depósitos superficiais e subsuperficiais de água. Nessas áreas ocorrem solos escuros "barro preto" (Nitossolo Vermelho acrescido de matéria 
orgânica), alta fertilidade, argilosos e permanecem úmidos na maior parte do ano. Esta se configura como uma área propícia à deposição de grande volume de sedimentos transportados das partes mais altas do relevo local, os produtores identificam esse processo de sedimentação como “aterrar”, o que ocasiona a elevação do nível de base das partes baixas (alvéolos). Para eles esse processo também é responsável pelo assoreamento dos cursos d'água e açudes. Usado principalmente na cultura do arroz, devido à umidade presente em grande parte do ano, e árvores frutíferas como goiabeiras, mangueiras, laranjeiras e bananeiras.

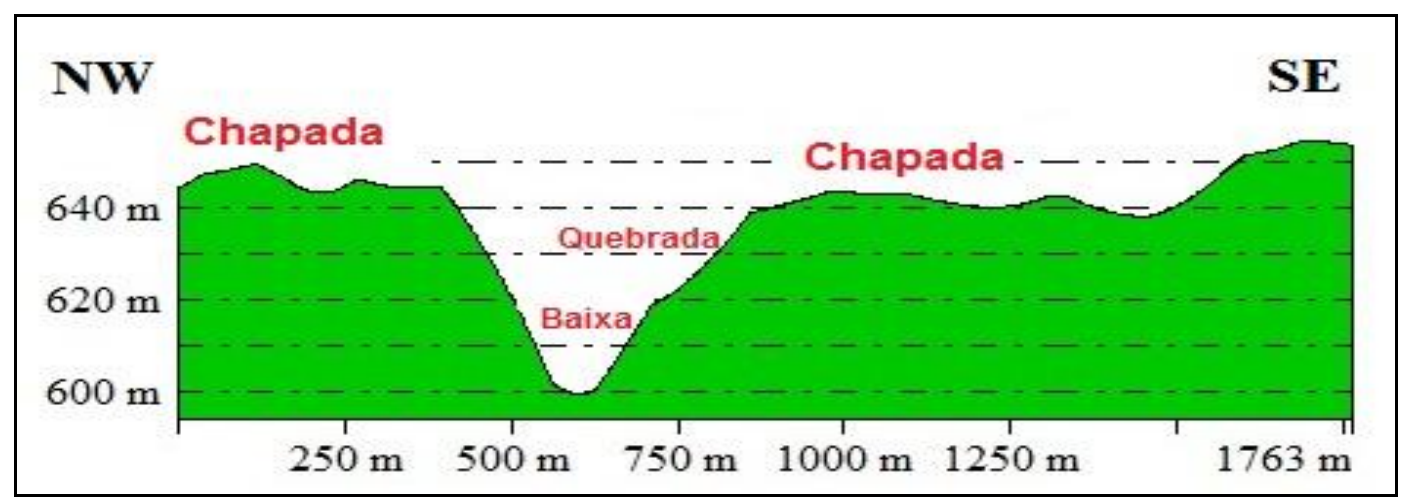

Figura 2: Perfil topográfico demonstrativo das unidades etnogeomorfológicas. 


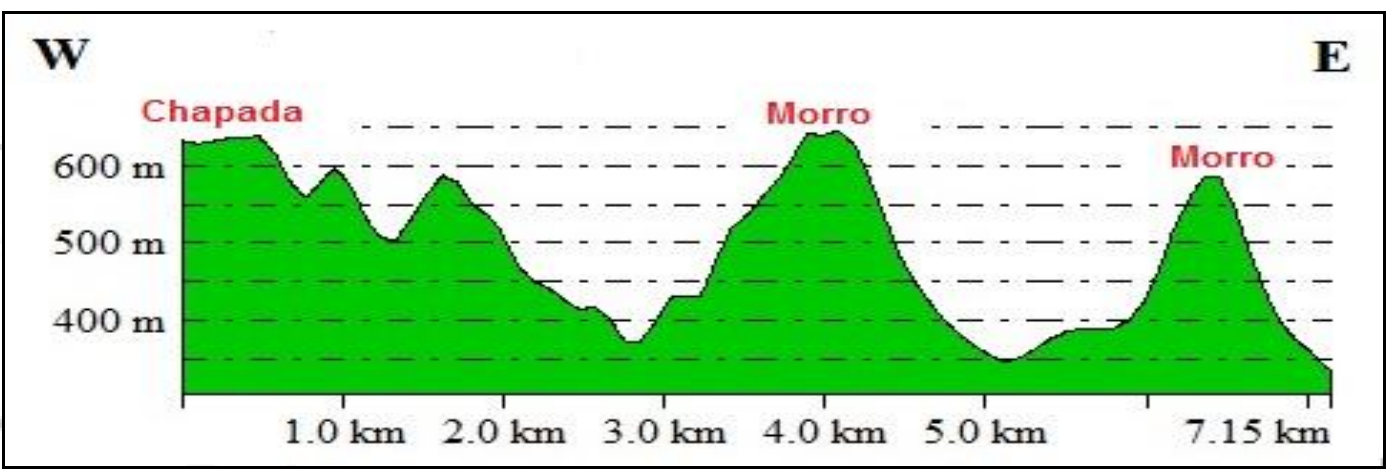

Figura 3: Perfil topográfico demonstrativo das unidades etnogeomorfológicas.

No distrito de Betânia, município de Farias Brito, foram alvo da pesquisa mais três cominidades, sítio Motas, sítio São João e sítio Várzea. Ao todo foram identificadas cinco unidades etnogeomorfológicas.

Serra - Corresponde ao Maciço Residual, conhecido popularmente como "Serra do Quincuncá" em toda a sua extensão. São identificados, aqui, a presenção de um solo avermelhado, considerado de boa fertilidade, chamado de "terra vermelha" (Nitossolo Vermelho). Nessas áreas, também denominadas de “terra despenhada" ocorrem processos erosivos chamados de "barrocão” (voçorocas), "grotas" (ravinas) e "buracos" (sulcos e microrravinas). Quanto aos processos gravitacionais de massa, apenas um produtor rural descreveu o rolamento de blocos rochosos nessa unidade. Explica que esse processo ocorre pela influencia de chuvas intensas: "é quando a peda descola do chão (...) ela desce levando tudo!’. Nessa área são feitos cultivos de todos os tipos de cultura, desde sementes 
que precisam de pouca umidade como o feijão, às que necessitam de umidade elevada do solo como o arroz.

Serrinha - Colina residual localizada a margem direita do rio Cariús, paralelo a Serra do Quincuncá. Sua altimetria não ultrapassa os 500 metros. Há a predominancia de solo caracterizado como arenoso, de cor esbranquiçada com presença de materiais primários, considerado de baixa fertilidade, chamado de "terra ariúsca" (Neossolo Litólico). Foram identificados processos denominados de "grotas" (ravinas e voçorocas) "rachão" (ravinas e microrravinas) "buracos no chão" (erosão difusa). Devido a declividades essas áreas são adequadas apenas para o cultivo de feijão.

Morro - Colina Residual. Solo arenoso, de cor esbranquiçada, pedregoso e de baixo a médio teor de fertilidade. Também denominado de "terra despenhada", aqui acontecem processos menos intensos que na unidade anterior, que são as "grotas" (ravinas) e os "buracos" (sulcos e microrravinas). Usado principalmente para o cultivo de feijão, grão que não necessita de muita umidade para se desenvolver. Outras culturas como o milho, a fava e o capim também são cultivados nessas áreas.

Tabuleiro - São terrenos com altimetrias intermediárias entre as colinas residuais e as áreas de várzea. Recebe esse nome devido as características do solo que se desenvolvem em sua área de abrangência, caracterizado como um solo 
avermelhado, de baixa fertilidade, vegetação esparsa, chamado de "terra escravada", o que indica início de desertificação desse solo. Nessas áreas ocorrem processos erosivos em estágio avançados, chamados de "barrocão" e "levada", que correspondem às Voçorocas.

Baixi - Áreas de várzea localizadas as margens do rio Cariús. Aqui foi relatada a existência de um solo de cor escura, alta fertilidade, maciez, e que é chamado popularmente de "barro preto", "terra preta" (Neossolo Flúvico acrescido de matéria orgânica). Não foram relatadas a ocorrência de processos erosivos nessas áreas. E os cultivos realizados são diversificados, pois é apropriado a todos os tipos de cultura, principalmente o arroz, devido à umidade constante do solo.

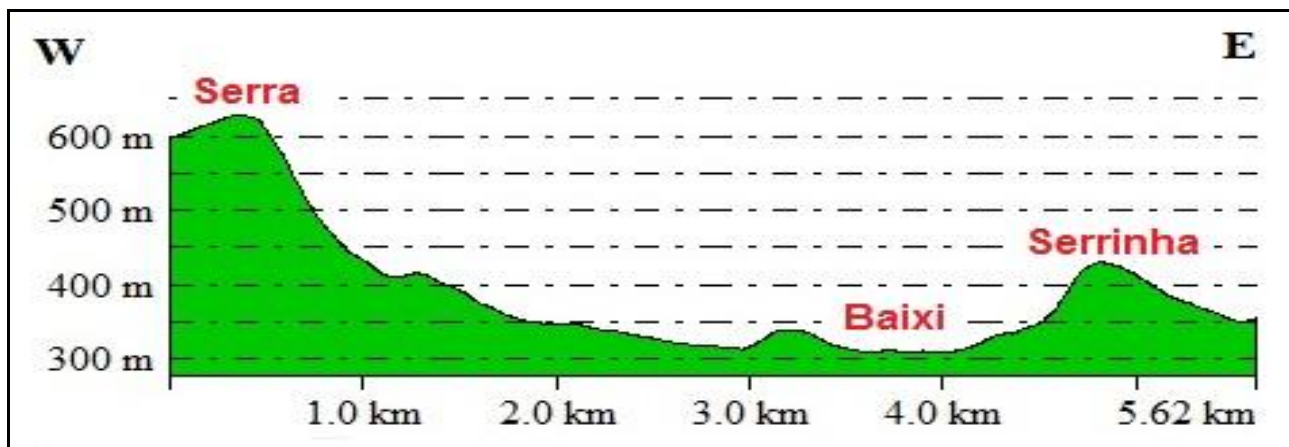

Figuras 4: Perfil topográfico demonstrativo das unidades etnogeomorfológicas. 


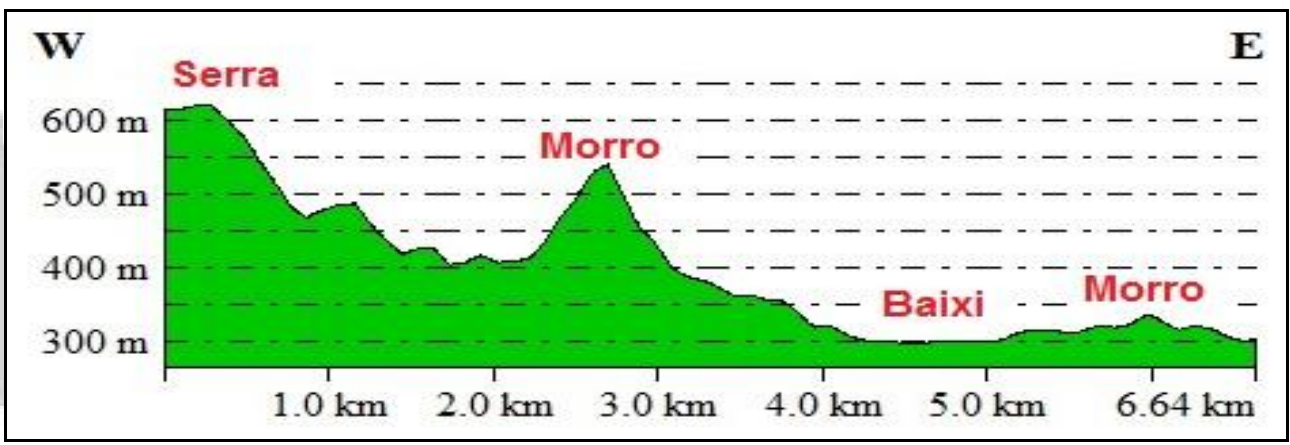

Figura 5: Perfil topográfico demonstrativo das unidades etnogeomorfológicas.

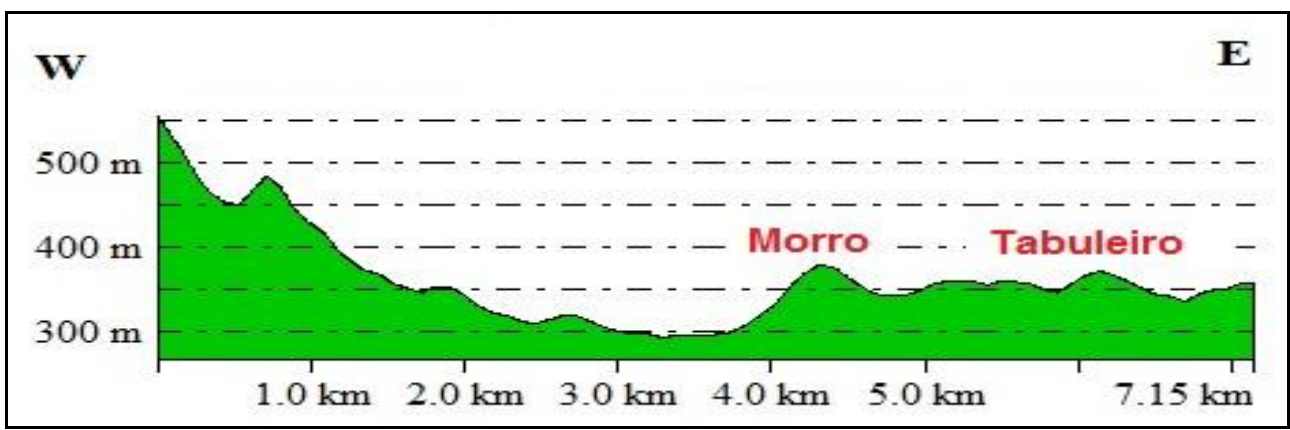

Figura 6: Perfil topográfico demonstrativo das unidades etnogeomorfológicas.

Já no distrito de Granjeiro (município de Granjeiro) foram pesquisadas outras três comunidades, sítio Canabrava dos Ferreira, sítio Canabrava dos Gregório e sítio Umari. Aqui, encontramos uma menor diversidade de nomenclaturas em relação ao solo, relevo e aos processos morfoesculturadores, ao todo foram três.

Serra/Terra de alto - Maciços residuais com cotas altimétricas atingindo os 670 metros. Aqui estão presentes solos arenosos e pedregosos, chamados de "terra branca" ou "terra arenosa" que correspondem ao Neossolo Litólico. Aqui se 
encontra, também, a "terra vermelha" ou "barro vermelho", correspondente ao Argissolo Vermelho. Não foram relatadas presença de processos erosivos nessas áreas. Todos identificaram movimentos gravitacionais de massa nessas áreas e denominam-nos de "desabamento" ou "deslizamento" e apontam como causa o grande volume de chuvas ocorridas no ano de 2004. Segundo os entrevistados nessa unidade se encontram solos de baixa fertilidade, que são utilizados apenas nos cultivos do milho, feijão e fava.

Quebrada - Encostas íngremes que intermediam a "serra" e o "baixi". Aqui foram descritos os mesmos tipos de solo da unidade anterior. Apenas um entrevistado identificou processos erosivos nessa área ao qual denominou de "grota pequena" a erosão difusa e microrravinas e de "erosão grande" as ravinas e voçorocas. Quanto aos movimentos gravitacionais de massa, dois produtores identificaram esse processo, e justificaram que acontece quando as terras são "massentas", não apontaram nenhuma nomenclatura específica, tampouco as causas desse processo. Por conta da declividade e da qualidade do solo, o cultivo indicado para essas áreas é o do feijão.

Baixi - Áreas de várzeas de baixas declividades. Aqui predominam solos férteis, úmidos e macios, chamam de "terra de barro" ou "barro preto" (Neossolo Flúvico). Sobre os processos morfoesculturadores, aqui foram identificados pelos produtores todos os estágios de evolução dos processos erosivos, desde a erosão difusa, chamada de "grota miudinha"; as microrravinas de "rachão"; as ravinas e 
voçorocas de "grota", "grotona" e "sucarvão”. De acordo com os relatos dos entrevistados, nessas áreas ocorrem a sedimentação, porém não atribuem nenhuma nomenclatura específica a eles. Apenas afirmam que durante os "deslizamentos" a “terra do alto vai descendo pra baixo". São feitos todos os tipos de cultivo, principalmente o arroz, por conta da umidade, e a pastagem dos animais.

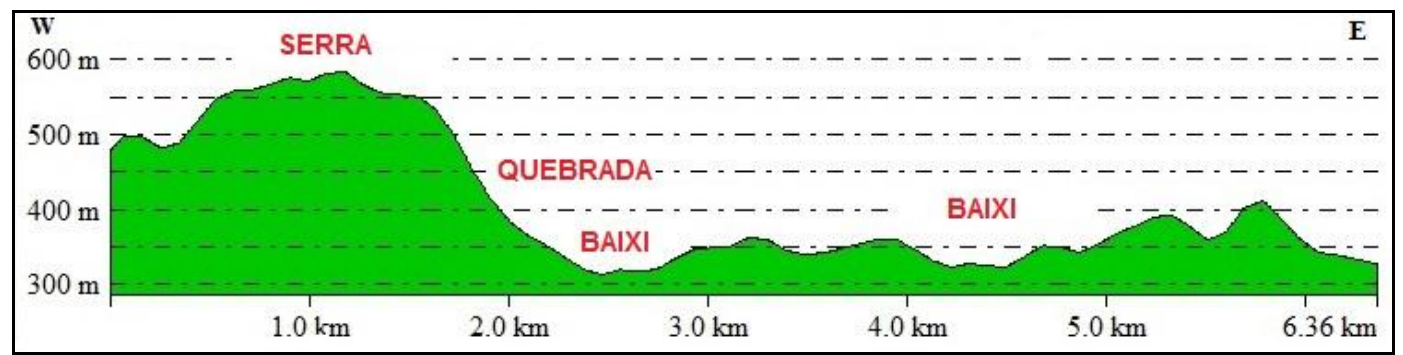

Figura 06. Perfil topográfico demonstrativo das unidades etnogeomorfológicas.

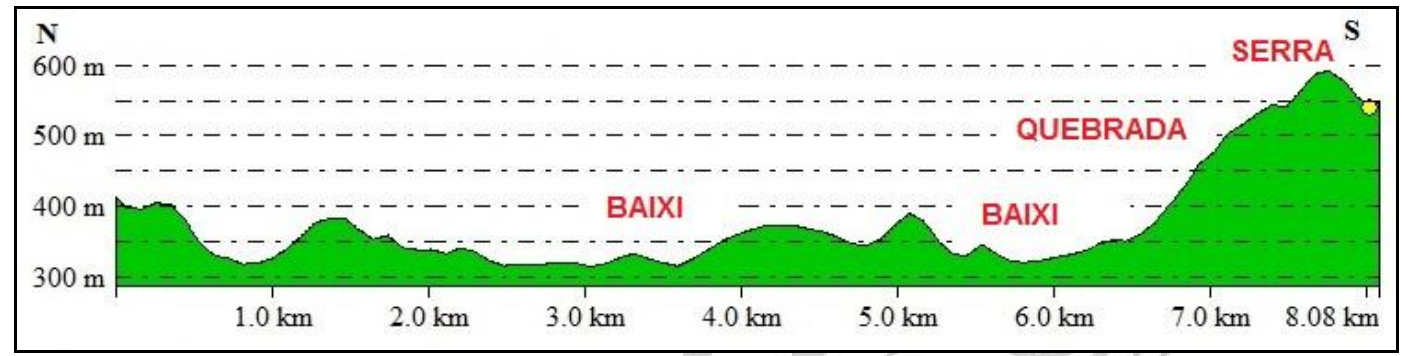

Figura 07. Perfil topográfico demonstrativo das unidades etnogeomorfológicas.

Em relação à forma como o solo é preparado para o cultivo, existem duas formas de se preparar o solo que são realizadas de acordo com o tipo de solo e a declividade do terreno. 
Nas áreas denominadas de "chapada" e "baixi", onde a declividade é baixa e a condição do solo, que geralmente apresenta pouca pedregosidade, umidade, profundidade, é feito o que os produtores chamam de "tombar", que consiste na aragem do solo com o uso de máquinas agrícolas.

Para que esse processo seja favorável à conservação do solo, os entrevistados afirmam que é preciso que se deixe o "bagaço" (restos da vegetação e do plantio anterior) para que seja misturado ao solo e sirva como adubo, além de funcionar com um suporte aos grãos do solo suscetíveis ao arraste pela erosão laminar. Afirmam também que esse processo permite que o solo se mantenha a fértil por mais tempo, apesar de agredi-lo, pois permanece desnudo por muitos anos sendo explorado a cada período chuvoso e seu processo de recuperação dura em torno de cinco anos. Seu tempo útil para o cultivo, de acordo com os entrevistados é de seis a oito anos.

Já nas outras unidades denominadas de "serra", "serrinha", "morro" e "quebrada", por conta da declividade e que na maioria das vezes se tratam de áreas com presença de Neossolo Litólico, o processo descrito acima não se aplica nessas áreas. Sendo assim, os produtores optam pela "broca", que consiste no desmatamento, para posteriormente fazerem a queimada dos restos da cobertura vegetal no local. Reconhecem que essa prática agride mais o solo, e os processos erosivos ocorrem com mais intensidade. Segundo os entrevistados, um solo que é preparado dessa forma, leva apenas dois ou três anos para perder sua fertilidade 
natural e para se recuperar é necessário que permaneça em repouso durante oito a dez anos.

Diante do exposto, é notório que pequeno produtor rural usa do seu conhecimento etnogeomorfológico para organizar seu espaço produtivo, mediante as limitações impostas pelo relevo, seus processos e os tipos de solo correlatos. As variáveis expostas aqui refletem as práticas de ordenamento territorial da sociedade camponesa.

\section{CONSIDERAÇÕES FINAIS}

A partir de todo o levantamento e interpretação das informações e conhecimentos obtidos nas fases de laboratório e campo, pudemos constatar a importância que o solo e o relevo têm para o pequeno produtor rural e o quanto ele, através do método empírico (suas observações e experiências cotidianas), e também da transmissão de conhecimentos vernaculares feita pelos seus genitores, entendem essa relação intrínseca entre esses dois elementos cruciais para o desenvolvimento de suas atividades agropecuárias. Além de identificarem o papel importante que todos os elementos naturais ocupam na dinâmica ambiental.

Com isso, destaca-se aqui, a importância das pesquisas etnográficas e da valorização do saber popular em relação ao meio ambiente e sua dinâmica, pois, a partir do conhecimento das fragilidades e potencialidades do ecossistema de que dependem, os sertanejos planejam e ordenam seu território na busca de uma 
melhor viabilização de suas atividades econômicas, tendo em vista a conservação do meio ambiente. As origens desses conhecimentos, remontantes a passados longínquos, podem estar vinculados aos saberes dos povos que habitaram o sertão nordestino antes da chegada do conquistador europeu. Essa pesquisa abre possibilidades para, a posteriori, buscar as raízes desses conhecimentos.

\section{REFERÊNCIAS BIBLIOGRÁFICAS}

BRANDÃO, Ana Maria de Paiva Macedo; RUSSO, Paulo Roberto; FIALHO, Edson Soares. Planejamento e clima urbano. Revista da Pós-graduação em geografia. UFRJ/PPGG: Rio de Janeiro, 2001.

FUNCEME, Levantamento de Reconhecimento de Média Intensidade de Solos Mesorregião do Sul Cearense. Fundação Cearense de meteorologia e Recursos Hídricos: Fortaleza, 2012.

FUNCEME. Zoneamento geoambiental do estado do Ceará: parte II Mesorregião do Sul Cearense. Fundação Cearense de meteorologia e Recursos Hídricos: Fortaleza, 2006.

IBGE. Instituto Brasileiro de Geografia e Estatística. Cidades@: Farias Brito. Disponível em: $<$ http://www.cidades.ibge.gov.br/xtras/perfil.php?lang=\&codmun=230430> Acesso em: 24/11/2015.

IBGE. Instituto Brasileiro de Geografia e Estatística. Cidades@: Granjeiro. Disponível em: $<$ http://www.cidades.ibge.gov.br/xtras/perfil.php?lang=\& codmun=230480> Acesso em: 02/09/2016.

IPECE. Ceará em mapas Tipos Climáticos. Instituto de Pesquisa e Estratégia Econômica do Ceará: Fortaleza, 2007. Disponível em: http://www2.ipece.ce.gov.br/atlas/capitulo1/12/126x.htm> Acesso em: 03/07/2016. 
IPECE. Perfil Básico Municipal Farias Brito 2015. Instituto de Pesquisa e estratégia Econômica do Ceará: Fortaleza, 2015. Disponível em:

$<$ http://www.ipece.ce.gov.br/publicacoes/perfil basico/pbm-2015/Farias_Brito.pdf $>$ Acesso em: 15/11/2015.

IPECE. Perfil Básico Municipal Granjeiro 2015. Instituto de Pesquisa e estratégia Econômica do Ceará: Fortaleza, 2015. Disponível em:

$<$ http://www.ipece.ce.gov.br/publicacoes/perfil_basico/pbm-2015/Granjeiro.pdf $>$ Acesso em: 15/11/2015.

MILLER, F. S. Arqueologia e Etnografia. ARQUEOLOGIA DO RN: BALANÇOS E PERSPECTIVAS. 1 ed. Natal: EDUFRN-Editora da UFRN, 2014, v. 1, p. 117-125.

MIRANDA, E. E. de; (Coord.). Brasil em Relevo. Campinas: Embrapa Monitoramento por Satélite, 2005. Disponível em: < http://www.relevobr.cnpm.embrapa.br $>$ Acesso em: $12 / 07 / 2014$.

RIBEIRO, Simone Cardoso. Etnogeomorfologia Sertaneja: proposta de classificação das paisagens da sub-bacia do rio Salgado/CE com base no conhecimento tradicional sobre relevo e seus processos. Editora RDS: Crato, 2014.

ROSS, Jurandyr Luciano Sanches. Análise empírica das fragilidades dos ambientes naturais e antropizados. FFLCH/USP: São Paulo, 1993.

TOLEDO, Victor Manuel; BARRERA-BASSOLS, Narciso. A etnoecologia: uma ciência pós-normal que estuda as sabedorias tradicionais. R. Desenvolvimento e Meio Ambiente, Ed. UFPR: Paraná, 2009. Disponível em:

$<$ http://ojs.c3sl.ufpr.br/ojs2/index.php/made/article/view/14519/10948>.

Acesso em: 27/08/2014.

Indexadores: Latindex, ISI, Google Scholar 